\title{
Editorial
}

\section{State-of-the-Art Laser Gas Sensing Technologies}

\author{
Yufei Ma ${ }^{1, *(\mathbb{D})}$, Aurore Vicet ${ }^{2}$ and Karol Krzempek ${ }^{3}$ \\ 1 National Key Laboratory of Science and Technology on Tunable Laser, Harbin Institute of Technology, \\ Harbin 150001, China \\ 2 IES, Univ. Montpellier, CNRS, 34000 Montpellier, France; aurore.vicet@umontpellier.fr \\ 3 Laser and Fiber Electronics Group, Wroclaw University of Science and Technology, 50-730 Wroclaw, Poland; \\ karol.krzempek@pwr.edu.pl \\ * Correspondence: mayufei@hit.edu.cn; Tel.: +86-451-8641-3161
}

Received: 21 November 2019; Accepted: 6 January 2020; Published: 7 January 2020

check for updates

\section{Introduction}

The increasing desire to detect and monitor in different fields [1-4] such as in environmental air, life sciences, medical diagnostics, and planetary exploration demand the development of innovative sensing systems. Laser spectroscopy-based techniques have the advantages of high sensitivity, non-invasiveness and in situ, real-time observation [5-7]. Because of these merits, we introduced state-of-the-art laser gas sensing technologies in this Special Issue. A total of 30 papers was received for consideration of publication. Among them, six manuscripts were rejected by the editor in the initial check process without peer review. The remaining manuscripts were all reviewed by at least two reputed reviewers in related fields from the USA, France, Italy, Germany, Russia, and so on. Finally, 16 manuscripts were accepted for publication in Applied Sciences-Basel. We would like to thank all of these numerous reviewers for their effort.

\section{Main Content of the Special Issue}

The recent advance in laser sources and detectors has opened up new opportunities for laser spectroscopy-based sensing and detecting techniques. Furthermore, the new technique has helped to promote its applications. Therefore, in this Special Issue, papers focus on novel laser sources and advanced sensing methods and their applications.

With respect to the laser sources aspect, three papers are concerned. All of them are related to mid-infrared lasers, which are beneficial to laser spectroscopy methods due to the strongest fundamental absorption bands of gas molecules located in this wavelength region. The first paper, authored by J. Zhao, P. Cheng, F. Xu, X. Zhou, J. Tang, Y. Liu, and G. Wang presents a continuouswave single-frequency singly-resonant mid-infrared optical parametric oscillator (OPO) with emission wavelength at $3.68 \mu \mathrm{m}$ [8]. The output power of more than $1 \mathrm{~W}$ indicated the high output level. Therefore, such a source is especially beneficial to power related laser-based gas detection techniques, such as photoacoustic and photothermal spectroscopy $[9,10]$. The second paper submitted by $\mathrm{W}$. Wang, L. Li, H. Zhang, J. Qin, Y. Lu, C. Xu, S. Li, Y. Shen, W. Yang, Y. Yang, and X. Yu reports a pulsed $\mathrm{Tm}, \mathrm{Ho}: \mathrm{LuVO}_{4}$ solid-state laser with a repetition rate of $54.5 \mathrm{kHz}$ and an output power of $1034 \mathrm{~mW}$. The emission wavelength shifted from $2075.02 \mathrm{~nm}$ to $2057.03 \mathrm{~nm}$ when the operation mode was switched from continuous wave to Q-switched [11]. The last paper in this section, authored by D. Yu, Y. He, K. Zhang, Q. Pan, F. Chen, and L. Guo, is about a compact thermal control system for a tunable mid-infrared solid-state laser, which could be used to improve environmental temperature adaptability and solve heat dissipation problems for mid-infrared lasers [12].

In the gas sensing aspect of this Special Issue, Y. F. Ma presents a review paper about recent advances in the quartz tuning fork based on photoacoustic detection [13], while K. Krzempek summarizes the 
research progress in gas sensing by photothermal spectroscopy [14]. Both techniques are based on the photoacoustic effect. Another review paper concerned with femtosecond laser-induced emission spectroscopy and its application in combustion and flow field diagnostics was presented by $\mathrm{B}$. $\mathrm{Li}$, D. Zhang, J. Liu, Y. Tian, Q. Gao, and Z. Li [15]. The last three review papers, authored by Z. Du, F. Wang, and X. Chao, respectively, mainly focus on direct laser absorption spectroscopy, especially in the mid-infrared region [16-18]. All the above review papers presented a full discussion with regard to the related technical field of gas sensing. The remaining papers report on the technical research of gas detection based on direct laser absorption spectroscopy [19-25]. The target analytes were acetylene $\left(\mathrm{C}_{2} \mathrm{H}_{2}\right)$ [19], methane $\left(\mathrm{CH}_{4}\right)$ [20], oxygen $\left(\mathrm{O}_{2}\right)$ [21], and ${ }^{13} \mathrm{CO}_{2} /{ }^{12} \mathrm{CO}_{2}$ isotopic ratio [22]. The corresponding sensors were used for the monitoring of power plant exhausts [23] and vision imaging [24].

Author Contributions: Y.M.: writing original draft; A.V. and K.K.: reviewing and editing. All authors have read and agreed to the published version of the manuscript.

Funding: National Natural Science Foundation of China (No. 61875047 and 61505041), Natural Science Foundation of Heilongjiang Province of China (No. YQ2019F006), Fundamental Research Funds for the Central Universities, Financial Grant from the Heilongjiang Province Postdoctoral Foundation (No. LBH-Q18052).

Acknowledgments: We would like to sincerely thank our Section Managing Editor, Marin Ma (marin.ma@mdpi.com), for all the efforts she has made for this Special Issue and Xiaoyan Chen, Senior Editor over the past few months, both of them from the MDPI Branch Office, Beijing.

Conflicts of Interest: The authors declare no conflict of interest.

\section{References}

1. Ravishankara, A.R.; Daniel, J.S.; Portmann, R.W. Nitrous oxide $\left(\mathrm{N}_{2} \mathrm{O}\right)$ : The dominant ozone-depleting substance emitted in the 21st century. Science 2009, 326, 123-125. [CrossRef] [PubMed]

2. Milde, T.; Hoppe, M.; Tatenguem, H.; Mordmüller, M.; O'Gorman, J.; Willer, U.; Schade, W.; Sacher, J. QEPAS sensor for breath analysis: A behavior of pressure. Appl. Opt. 2018, 57, C120-C127. [CrossRef] [PubMed]

3. Ma, Y.F.; Lewicki, R.; Razeghi, M.; Tittel, F.K. QEPAS based ppb-level detection of $\mathrm{CO}$ and $\mathrm{N}_{2} \mathrm{O}$ using a high power CW DFB-QCL. Opt. Express 2013, 21, 1008-1019. [CrossRef] [PubMed]

4. Bradshaw, J.L.; Bruno, J.D.; Lascola, K.M.; Leavitt, R.P.; Pham, J.T.; Towner, F.J; Sonnenfroh, D.M.; Parameswaran, K.R. Small low-power consumption CO-sensor for post-fire cleanup aboard spacecraft. In Proceedings of the Next-Generation Spectroscopic Technologies IV, Orlando, FL, USA, 12 May 2011; Society of Photo-Optical Instrumentation Engineers: Bellingham, WA, USA, 2011; Volume 8032, p. 80320D.

5. He, Y.; Ma, Y.F.; Tong, Y.; Yu, X.; Peng, Z.F.; Gao, J.; Tittel, F.K. Long distance, distributed gas sensing based on micro-nano fiber evanescent wave quartz-enhanced photoacoustic spectroscopy. Appl. Phys. Lett. 2017, 111, 241102. [CrossRef]

6. He, Y.; Ma, Y.F.; Tong, Y.; Yu, X.; Tittel, F.K. Ultra-high sensitive light-induced thermoelastic spectroscopy sensor with a high Q-factor quartz tuning fork and a multipass cell. Opt. Lett. 2019, 44, 1904-1907. [CrossRef]

7. Ma, Y.F.; He, Y.; Tong, Y.; Yu, X.; Tittel, F.K. Quartz-tuning-fork enhanced photothermal spectroscopy for ultra-high sensitive trace gas detection. Opt. Express 2018, 26, 32103-32110. [CrossRef]

8. Zhao, J.; Cheng, P.; Xu, F.; Zhou, X.; Tang, J.; Liu, Y.; Wang, G. Watt-Level Continuous-wave single-frequency mid-infrared optical parametric oscillator based on MgO:PPLN at $3.68 \mu \mathrm{m}$. Appl. Sci. 2018, 8, 1345. [CrossRef]

9. Krzempek, K.; Dudzik, G.; Abramski, K. Photothermal spectroscopy of $\mathrm{CO}_{2}$ in an intracavity mode-locked fiber laser configuration. Opt. Express 2018, 26, 28861-28871. [CrossRef]

10. Rousseau, R.; Loghmari, Z.; Bahriz, M.; Chamassi, K.; Teissier, R.; Baranov, A.N.; Vicet, A. Off-beam QEPAS sensor using an 11- $\mu \mathrm{m}$ DFB-QCL with an optimized acoustic resonator. Opt. Express 2018, 27, 7435-7446. [CrossRef]

11. Wang, W.; Li, L.; Zhang, H.; Qin, J.; Lu, Y.; Xu, C.; Li, S.; Shen, Y.; Yang, W.; Yang, Y.; et al. Passively Q-switched operation of a Tm,Ho:LuVO 4 laser with a graphene saturable absorber. Appl. Sci. 2018, 8, 954. [CrossRef] 
12. Yu, D.; He, Y.; Zhang, K.; Pan, Q.; Chen, F.; Guo, L. A tunable mid-infrared solid-state laser with a compact thermal control system. Appl. Sci. 2018, 8, 878. [CrossRef]

13. Ma, Y. Review of recent advances in QEPAS-based trace gas sensing. Appl. Sci. 2018, 8, 1822. [CrossRef]

14. Krzempek, K. A review of photothermal detection techniques for gas sensing applications. Appl. Sci. 2019, 9, 2826. [CrossRef]

15. Li, B.; Zhang, D.; Liu, J.; Tian, Y.; Gao, Q.; Li, Z. A review of femtosecond laser-induced emission techniques for combustion and flow field diagnostics. Appl. Sci. 2019, 9, 1906. [CrossRef]

16. Du, Z.; Zhang, S.; Li, J.; Gao, N.; Tong, K. Mid-infrared tunable laser-based broadband fingerprint absorption spectroscopy for trace gas sensing: A Review. Appl. Sci. 2019, 9, 338. [CrossRef]

17. Wang, F.; Jia, S.; Wang, Y.; Tang, Z. Recent developments in modulation spectroscopy for methane detection based on tunable diode laser. Appl. Sci. 2019, 9, 2816. [CrossRef]

18. Wang, Z.; Fu, P.; Chao, X. Laser Absorption sensing systems: Challenges, modeling, and design optimization. Appl. Sci. 2019, 9, 2723. [CrossRef]

19. Wang, B.; Lu, H.; Chen, C.; Chen, L.; Lian, H.; Dai, T.; Chen, Y. Near-infrared $\mathrm{C}_{2} \mathrm{H}_{2}$ detection system based on single optical path time division multiplexing differential modulation technique and multi-reflection chamber. Appl. Sci. 2019, 9, 2637. [CrossRef]

20. Wang, Z.; Wang, S.; Kong, D.; Liu, S. Methane detection based on improved chicken algorithm optimization support vector machine. Appl. Sci. 2019, 9, 1761. [CrossRef]

21. Wang, C.; Zhang, Y.; Sun, J.; Li, J.; Luan, X.; Asundi, A. High-efficiency coupling method of the cradient-index fiber probe and hollow-core photonic crystal fiber. Appl. Sci. 2019, 9, 2073. [CrossRef]

22. Zhang, H.; Wen, M.; Li, Y.; Wan, P.; Chen, C. High-precision ${ }^{13} \mathrm{CO}_{2} /{ }^{12} \mathrm{CO}_{2}$ isotopic ratio measurement using tunable diode laser absorption spectroscopy at $4.3 \mu \mathrm{m}$ for deep-sea natural gas hydrate exploration. Appl. Sci. 2019, 9, 3444. [CrossRef]

23. Zhu, X.; Yao, S.; Ren, W.; Lu, Z.; Li, Z. TDLAS Monitoring of carbon dioxide with temperature compensation in power plant exhausts. Appl. Sci. 2019, 9, 442. [CrossRef]

24. Wang, X.; Ouyang, J.; Wei, Y.; Liu, F.; Zhang, G. Real-time vision through haze based on polarization imaging. Appl. Sci. 2019, 9, 142. [CrossRef]

25. Zhou, X.; Yu, J.; Wang, L.; Zhang, Z. Investigating the relation between absorption and gas concentration in gas detection using a diffuse integrating cavity. Appl. Sci. 2018, 8, 1630. [CrossRef] 